\title{
Results From Australia's 2016 Report Card on Physical Activity for Children and Youth
}

\author{
Natasha K. Schranz, Timothy Olds, Roslyn Boyd, John Evans, Sjaan R. Gomersall, Louise Hardy, \\ Kylie Hesketh, David R. Lubans, Nicola D. Ridgers, Leon Straker, Stewart Vella, \\ Jenny Ziviani, and Grant R. Tomkinson
}

\begin{abstract}
Background: Two years on from the inaugural Active Healthy Kids Australia (AHKA) Physical Activity Report Card, there has been little to no change with the majority of Australian children still insufficiently active. Methods: The 2016 AHKA Report Card was developed using the best available national- and state-based physical activity data, which were evaluated by the AHKA Research Working Group using predetermined weighting criteria and benchmarks to assign letter grades to the 12 Report Card indicators. Results: In comparison with 2014, Overall Physical Activity Levels was again assigned a $D$ - with Organized Sport and Physical Activity Participation increasing to a $B$ (was $B$-) and Active Transport declining to a $C$ - (was $C$ ). The settings and sources of influence again performed well $(A$ - to a $C+)$, however Government Strategies and Investments saw a decline $(C+$ to a $D)$. The traits associated with physical activity were also graded poorly $(C$ - to a $D)$. Conclusions: Australian youth are insufficiently active and engage in high levels of screen-based sedentary behaviors. While a range of support structures exist, Australia lacks an overarching National Physical Activity Plan that would unify the country and encourage the cultural shift needed to face the inactivity crisis head on.
\end{abstract}

Keywords: public health, sedentary behavior

In 2014 Active Healthy Kids Australia (AHKA) released their inaugural Report Card on Physical Activity for Children and Youth, which highlighted that Australia was facing an "inactivity crisis" in addition to evidence of substantial declines in activity (across various domains (eg, active transport) over the past few decades. ${ }^{1}$ A child's daily activity levels can be accumulated from various domains that include organized sport, activity done at school, active transport, and active play; however, the majority of Australian 5- to 17-year-olds do not meet the Australian Physical Activity Guidelines. $^{2-5}$ This is despite the well-evidenced health-related benefits for children who accumulate at least 60 minutes of moderate-to-vigorous intensity physical activity (MVPA) every day: they are at a lower risk of overweight or obesity, type II diabetes, metabolic syndrome, and other comorbidities; they are more likely

Schranz and Olds are with the Alliance for Research in Exercise, Nutrition and Activity (ARENA), School of Health Sciences, University of South Australia. Boyd, Ziviani, and Gomersall are with the Faculty of Health and Behavioural Sciences, The University of Queensland. Evans is with the Faculty of Health, University of Technology Sydney. Hardy is with the Physical Activity, Nutrition, and Obesity Research Group, University of Sydney. Hesketh and Ridgers are with the School of Exercise \& Nutrition Sciences, Deakin University. Lubans is with the Faculty of Education and Arts, University of Newcastle. Straker is with the School of Physiotherapy, Curtin University. Vella is with the School of Education, University of Wollongong. Tomkinson is with the Dept of Kinesiology \& Public Health Education, University of North Dakota; and the Alliance for Research in Exercise, Nutrition and Activity (ARENA), School of Health Sciences, University of South Australia. Schranz (natasha.schranz@mymail.unisa. edu.au) is corresponding author. to have a higher level of aerobic fitness; and they are more likely to experience positive mental health. ${ }^{6,7}$ Australian children and youth live in a technology-driven society that perhaps does not prioritize movement as it should. The result of this appears to be that we have a generation of children who lack the physical literacy necessary to be physically, cognitively and psychosocially capable individuals, ${ }^{8-10}$ which is vital if we want Australian children and youth to engage in lifelong physical activity (PA) participation at an appropriate level now and in the future. A coordinated response involving the individual, families, schools and the broader community as well as local, state and federal governments is vital, to initiate innovative ways of positively impacting PA behaviors, infrastructure, policies, and cultural practices that support lifelong activity for all.

AHKA, which produces the Australian Physical Activity Report Card, is a collaboration among Australian experts in the field of children's PA and health research who have an interest in increasing the overall PA levels of young Australians children and youth. The Report Card is a vehicle that advocates for all Australian children and youth to be more physically active every day while also providing a surveillance mechanism at both the national and international level. There are 12 indicators within the AHKA Report Card to which letter grades are assigned to reflect the state of play as a nation for children's PA and its determinants. These 12 indicators include PA behaviors, the settings and sources of influence, and strategies and investments that impact these behaviors, plus attributes that relate to children's ability to perform PA. Active Healthy Kids Australia are committed to releasing Full Report Cards biennially that focus on all 12 PA indicators to align with the Active Healthy Kids Global Alliance Global Matrix. In alternating years AHKA will release Progress Report Cards that focus only on 1 PA indictor, the first Progress Report Card was released in 2015 and focused on Active Transport. 
The purpose of this manuscript is to summarize the methods and key findings of the 2016 AHKA Report Card. The Report Card synthesizes the best available national- and state-based PA data from 2010 onwards to assign letter grades to all 12 indicators.

\section{Methods}

The 2016 AHKA Report Card was developed by researchers from the University of South Australia (the Lead Research University for the Report Card) and an invited group of 13 researchers from 8 universities who comprised the AHKA Research Working Group (RWG). The AHKA RWG was responsible for (a) deciding which indicators (in addition to the 9 core indicators) would be assessed, (b) deciding how each indicator was operationalized (ie, the specific metrics/variables used to assign grades), (c) deciding which data sources were accessed to inform each of the grades, and (d) evaluating the synthesized data (at both a national- and state-level) to grade all 12 indicators using predetermined criteria and benchmarks and provide a confidence rating for the data used to inform each grade. In 2016, AHKA also worked collaboratively with the National Heart Foundation of Australia to develop a media strategy for the dissemination of the Report Card, following the success of the media coverage for the release of the 2014 AHKA Report Card which generated 870 national media stories and 11 million media impressions with an Advertising Space Rate equivalent of AU\$1.1 million.

The 2016 AHKA Report Card assigned grades to 12 indicators. Nine of which are core indicators endorsed by the Active Healthy Kids Global Alliance (AHKGA) ${ }^{11}$ and 3 additional indicators (identified by the * below) that the RWG chose to include within the Australian Report Card as they resonate within the Australian culture as behaviors that contribute to overall physical levels or traits that impact/are impacted by PA. All indicators are clustered under the categories Overall Physical Activity Levels (\#1 to 6), Settings and Sources of Influence (\#7 to 9), Strategies and Investments (\#10), and Traits (\#11 and 12), including:

1. Overall Physical Activity Levels

2. Organized Sport and Physical Activity Participation

3. Physical Activity in Schools*

4. Active Play

5. Active Transport

6. Sedentary Behaviors

7. Family and Peers-infrastructure, support, parental/peer behaviors

8. School—infrastructure, policies, and programs

9. Community and the Built Environment-infrastructure, policies, programs, safety

10. Government-strategies, policies, and investments

11. Physical Fitness*

12. Movement Skills*

The 2016 AHKA Report Card used a number of data sources that were both national- and state-based to inform each of the grades. Where available, nationally representative data were preferred over state-based data, Table 1 shows the surveys used to provide evidence for each of the grades assigned to each indicator.

Using a grading framework, grades were assigned by consensus among the RWG after a 2-day face-to-face meeting where current evidence was assessed against benchmarks in addition to an assess- ment of changes from 2014 and the presence of disparities (eg, gender, age). This grading framework, endorsed by AHKGA and harmonized across all countries participating in the Global Matrix 2.0, was $A$, succeeding with a large majority of children and young people ( $81 \%$ to $100 \%) ; B$, succeeding with well over half of children and young people (61\% to $80 \%)$; $C$, succeeding with about half of children and young people ( $41 \%$ to $60 \%$ ); $D$, succeeding with less than half, but some, children and young people (21\% to $40 \%) ; F$, succeeding with very few children and young people (0\% to $20 \%$ ); and $I N C$ (incomplete), no available data are truly reflective of what the indicator represents or a consensus on how to operationalize the indicator could not be reached. For the instances when the proportion of children succeeding fell within the upper- or lower-end of a range for a given grade, a plus or a minus were assigned respectively (eg, $76 \%$ of children succeeding would be assigned a $B+$ ). The RWG also graded the confidence they had in the data supporting the indicator grades assigned on a 1-, 2-, and 3-star scale based on a consensus of the representativeness (eg, national vs. state-based survey, sampling frame/procedure and response rate, age range of children surveyed, sample size obtained) and robustness (eg, how the question was asked, objective vs. subjective, reliability and validity data) of the data. The addition of the confidence rating has allowed grades to be assigned to specific indicators that were assigned 'Incompletes' in 2014 (ie, Physical Fitness and Movement Skills), as the grades assigned can now be interpreted in conjunction with the confidence rating given.

With the grades assigned, the RWG assessed whether a unique 'story' or theme emerged from the synthesized data. All ideas were thoroughly discussed before the RWG unanimously agreed on the 2016 Report Card cover story/theme.

\section{Results}

The 2016 AHKA Report Card is the second biennial assessment of PA for Australian children and youth (in alternating years AHKA release a Progress Report Card that focuses on one indicator, in 2015 the focus was on Active Transport ${ }^{12}$ ). Table 2 shows the 12 indicators, the corresponding grades and the confidence rating assigned and Figure 1 shows the front cover of the 2016 AHKA Report Card.

\section{Discussion}

Two years on from the inaugural AHKA Physical Activity Report Card published in $2014,{ }^{1}$ overall activity levels are still low and sedentary behaviors (operationalized as recreational screen-time due to available data) high despite having extensive infrastructure and initiatives in place to promote, support and facilitate PA participation across the home, school and community settings. So what is holding Australian children and youth back? It was this question that prompted another question and the theme of this year's Australian Report Card, "Do our kids have all the tools they need to be physically literate and engage in lifelong physical activity now and in the future?"

A physically literate child has the physical, cognitive and psychosocial capabilities required to engage in lifelong PA participation at an appropriate level. ${ }^{8-10}$ Children receive much support with their first steps into physical literacy (eg, learning to and being encouraged to walk) but this learning needs to continue throughout childhood and adolescence to ensure the continued development of physical literacy, which may in turn, initiate the cultural shift needed to witness real improvement in PA and sedentary behaviors. ${ }^{13}$ 


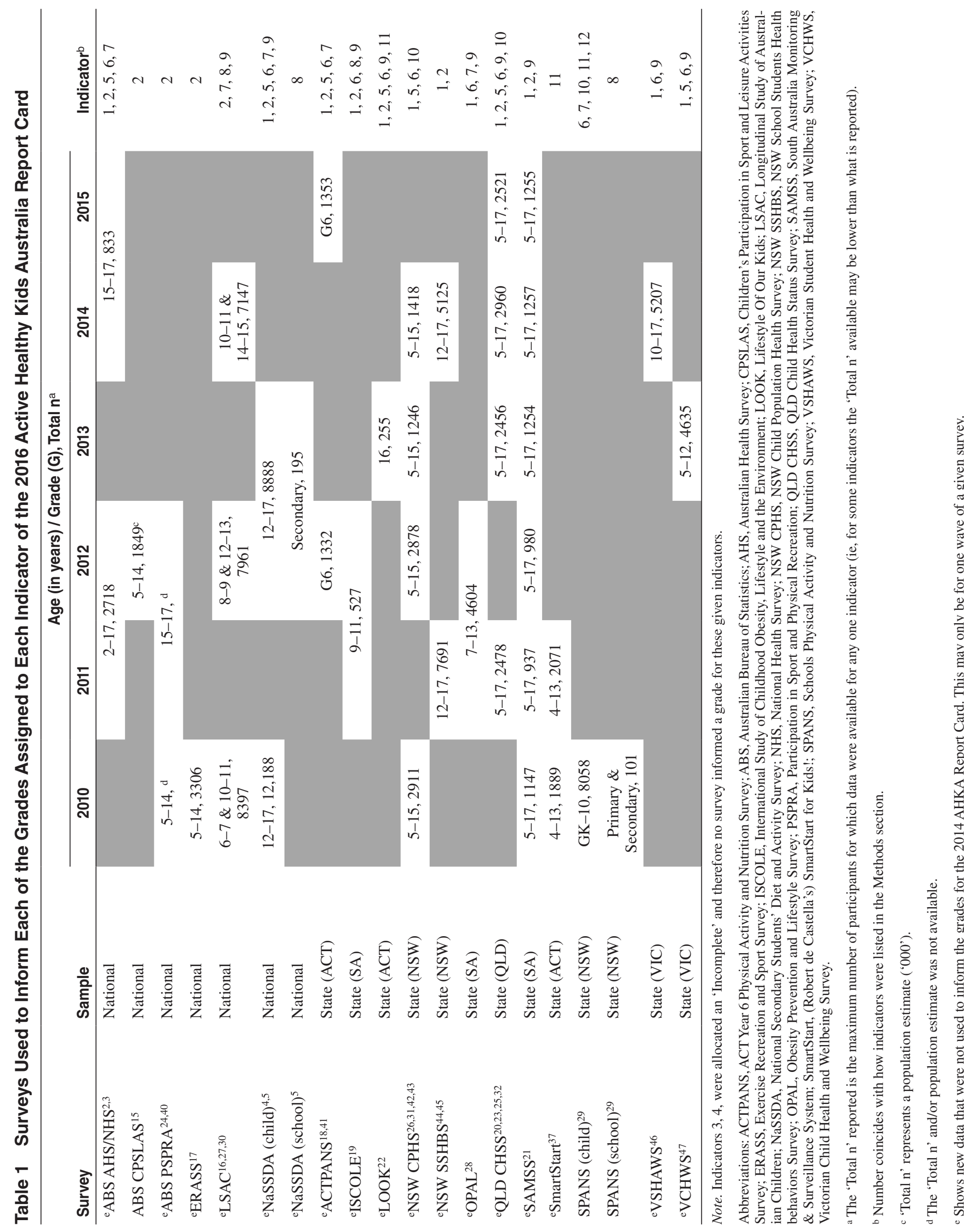




\section{Table 2 Grades According to Physical Activity Indicators in the 2016 Active Healthy Kids Australia Report Card}

\begin{tabular}{llcc}
\hline & Indicator & Grades & $\begin{array}{c}\text { Confidence } \\
\text { Rating }^{\mathrm{a}}\end{array}$ \\
\hline 1 & Overall Physical Activity Levels & $D-$ & $* *$ \\
2 & Organized Sport and Physical Activity Participation & $B$ & $* *$ \\
3 & Physical Activity in Schools & $I N C$ & N/A \\
4 & Active Play & $I N C$ & N/A \\
5 & Active Transport & $D-$ & $* *$ \\
6 & Sedentary Behaviors & $C+$ & $* *$ \\
7 & Family and Peers & $B-$ & $*$ \\
8 & School & $A-$ & $* *$ \\
9 & Community and the Built Environment & $D$ & $*$ \\
10 & Government Strategies and Investments & $C$ - & N/A \\
11 & Physical Fitness & $D$ & $* *$ \\
12 & Movement Skills & & $* *$ \\
\hline
\end{tabular}

Note. The grade for each indicator is based on the percentage of children and youth meeting a defined benchmark: $A$ is $81-100 \% ; B$ is $61-80 \%$; is $41-60 \%, D$ is $21-40 \%$; $F$ is $0-20 \%$; INC is Incomplete data.

\footnotetext{
a The confidence rating (a 3-star rating system was used) was assigned by the Research Working Group to reflect the representativeness (eg, national vs. state-based survey, sampling frame/procedure and response rate, age range of children surveyed, sample size obtained) and robustness (eg, how the question was asked, objective vs. subjective, reliability and validity data) of the data. Each star is represented by '*'.
}

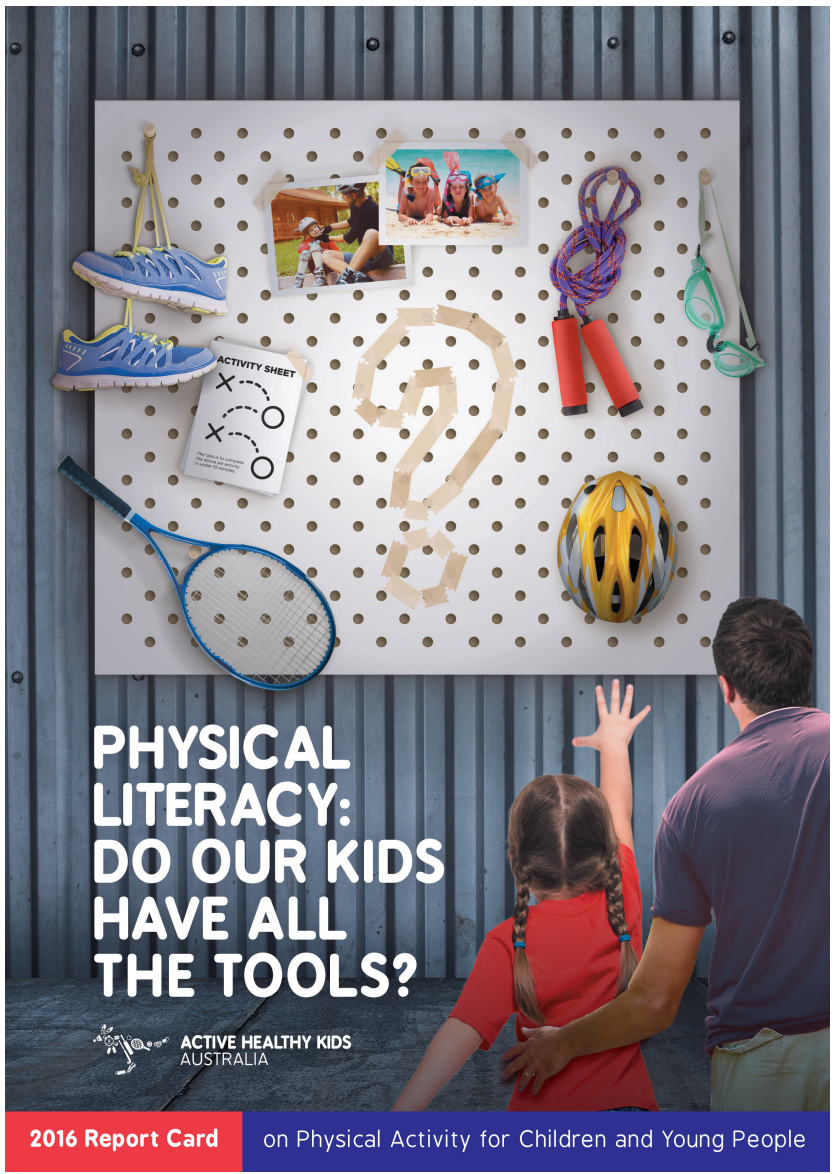

Figure 1 - Front cover of the 2016 Active Healthy Kids Australia Report Card on Physical Activity for Children and Youth.
The following sections: (a) report the grade allocated to each indicator; (b) explore time changes in grades between 2014 and 2016; and (c) state the rationale underpinning grade allocation.

\section{Overall Physical Activity Levels: D-}

As in 2014, Overall Physical Activity Levels was assigned a D-. While the 2016 grade was informed by new data (both national- and state-based) that was not available in 2014 (see Table 1), overall activity levels remain low with less than half, but some, children and young people being sufficiently active. National PA guidelines recommend that children aged 2 to 4 years should accumulate at least 180 minutes of PA (at any intensity) every day whereas 5- to 17-year-olds should accumulate at least 60 minutes of MVPA every day. ${ }^{14}$ While $72 \%$ of 2 - to 4 -year-olds currently meet the national PA guidelines, less than $20 \%$ of 5- to 17-year-olds accumulate 60 minutes of MVPA every day. ${ }^{2}$ Adherence to the PA guidelines declines as children transition into and move through adolescence, with only $15 \%$ to $18 \%$ of secondary school students aged 12 to 17 years ${ }^{4,5}$ and $6 \%$ of 15 - to 17 -year-olds ${ }^{3}$ meeting the guidelines. The confidence rating assigned to the data for this indicator was 2 stars (ie, representative but lacked robustness).

\section{Organized Sport and Physical Activity Participation: $B$}

Organized Sport and Physical Activity Participation was assigned a $B$, which is slightly better than the $B$ - in 2014 . The 2016 grade was informed by new national- and state-based data that provided additional clarity to the data available in 2014 (see Table 1). Current data show that $66 \%$ of 5 - to 14 -year-olds ${ }^{15}$ and $85 \%$ to $89 \%$ of 12 - to 17 -year-olds $s^{4,5}$ participated in organized sport or PA at least once during the previous 12 -month period; $64 \%$ of 5 - to 17 -year-olds participated during the past week ${ }^{2}$; and $81 \%$ of 10 - to 11 -year-olds 
and 14 - to 15 -year-olds ${ }^{16}$ and $71 \%$ of 5- to 14 -year-olds ${ }^{17}$ regularly participated during the past 12 months (ie, regular participation is at least once weekly for a sporting season/over 3 months/during previous school term). The assigned $B$ grade reflects the range of participation estimates reported, with supporting evidence from state-based data ${ }^{18-22,}$ however the RWG believe that it is the additional clarity (obtained from new data) that has driven the increased grade rather than actual participation rates increasing. The confidence rating assigned to the data for this indicator was 2 stars (ie, representative but lacked robustness).

\section{Physical Activity in Schools: INC}

Physical Activity in Schools (previously titled 'Physical Education and Physical Activity Participation in Schools') was assigned an $I N C$, consistent with the grade in 2014. This year the RWG decided that there were no national- or state-based data that truly reflected the behavior. At present, the only data available are limited nationaland state-based surveys $s^{4,5,23}$ that have reported the amount of time school students spend in Physical Education (PE) per week. However, to inform the grade, these data need to reflect time spent being physically active during $\mathrm{PE}$, rather than timetabled $\mathrm{PE}$ alone, and more data are required around time spent being physically active at other times within the school environment (eg, during recess and lunchtime, active lesson breaks, active lessons etc.) before a grade can be confidently allocated.

\section{Active Play: INC}

As in 2014, Active Play was assigned an INC. Two years on, the RWG still believe there is no single metric (with quality evidence available) that well defines what active play is and how we as a nation are performing. In addition to previous data, ${ }^{2,4,24}$ new national-based data were considered ${ }^{5,17}$ that report the participation rates, and time spent in, nonorganized activity during the past 12 months and/or past week. However, given the uncertainty regarding the definition of active play, and without a clear benchmark describing how much nonorganized activity is sufficient, further research and discussions are needed before a grade can be confidently allocated.

\section{Active Transportation: $\mathbf{C}$ -}

Active Transport was assigned a $C$-, which is slightly worse than the $C$ grade assigned in AHKA's 2014 Report Card and 2015 Progress Report Card on Active Transport. Previously, this core metric was operationalized as "the percentage of school students actively commuting to/from school (for all or some of the trip) at least once per week." However, this year the RWG decided to raise the bar for this indicator, and the primary metric used to assign the grade was changed to "the percentage of school students for which active transport is their usual mode of transport to and from school at least part of the way (defined as at least 5/10 trips or on at least 2.5/5 days)." New state-based data were considered in addition to the data considered in the 2015 Progress Report Card (see Table 1), which collectively showed that approximately $41 \%$ to $43 \%$ of secondary students $^{5,25}$ and $23 \%$ to $38 \%$ of primary school students ${ }^{18,19,22,25,26}$ use active transport as their 'usual mode' of transport to/from school at least part of the way. Even though new data were considered, the grade decline this year was a result of the RWG deciding to 'raise the bar' rather than actual participation rates declining. However, this is still meaningful given that less than half of Australian children and youth use active transport as their usual mode of transport to and from school. The confidence rating assigned to the data for this indicator was 2 stars (ie, representative but lacked robustness).

\section{Sedentary Behaviors: D-}

As in 2014, Sedentary Behaviors was assigned a $D$-. This grade reflects the proportion of Australian children and youth adhering to the national screen guidelines, which recommend that children and youth should not take part in more than 1 (2-4 years) or 2 (5-17 years) hours of screen activity for entertainment purposes every day. ${ }^{14}$ New national- and state-based data were considered (see Table 1 ), which, consistent with those data reported on in 2014 , showed that $26 \%$ of 2- to 4 -year-olds, $30 \%$ of 5 - to 17 -year-olds ${ }^{2}$ and $14 \%$ of 12 - to 17 -year-olds 5 meet the sedentary behavior screen time guidelines every day. The confidence rating assigned to the data for this indicator was 2 stars (ie, representative but lacked robustness).

\section{Family and Peers-Infrastructure, Support, Parental/Peer Behaviors: $\mathbf{C}_{+}$}

Family and Peers was assigned a grade of $C+$, which is slightly better than the $C$ in 2014. Consistent with the 2014 Report Card, this grade reflects a combination of primary metrics that provide insight into the infrastructure, support and role modeling behaviors Australian children and youth receive and experience within their family and peer environment. New national- and state-based data were available (see Table 1). It was reported that $16 \%$ of 2 - to 4-year-olds, ${ }^{2} 36 \%$ to $78 \%$ of primary school-aged children, ${ }^{2,16}$ and $69 \%$ to $85 \%$ of secondary school-aged children ${ }^{2,5,27}$ are able to use or access at least 1 screen-based device in their bedroom. The evidence shows that $82 \%$ to $97 \% 18,19,28$ and $75 \%{ }^{5}$ of primary and secondary school-aged children respectively receive some form of encouragement from their parents to be physically active. This same level of encouragement is received from their peers by $76 \%{ }^{28}$ and $54 \%{ }^{5}$ of primary and secondary school-aged children respectively. While $79 \%$ and $60 \%$ of parents with children aged 8 to 9 and 12 to 13 years, respectively, report that they play outside with their child at least once per week, ${ }^{27}$ modeling of PA behaviors was less prevalent with only $25 \%$ of mothers and $32 \%$ of fathers ${ }^{27}$ meeting the national PA guidelines for adults (which recommend accumulating at least 30 minutes of MVPA on most, preferably all, days of the week). ${ }^{14}$ The confidence rating assigned to the data for this indicator was 1 star (ie, representativeness and robustness are lacking).

\section{School-Infrastructure, Policies, and Programs: B-}

As in 2014, School was assigned a $B$-. The grade assigned to this indicator reflects a synthesis of data that combines a mix of primary metrics which represent the current infrastructure, policies and programs within the school environment to promote, support and facilitate PA. New national data for both primary and secondary schools were available (see Table 1). School teachers report that $75 \%$ and $98 \%$ of primary and secondary school students respectively have access to a specialist PE teacher. ${ }^{16}$ In addition, secondary schools employ (on average) 6 full-time PE teachers,${ }^{5}$ however, the qualifications of these PE teachers and whether they actually administer all PE classes is unknown. Teachers also report that $33 \%{ }^{16}$ and $8 \%{ }^{5}$ of primary and secondary school students respectively receive at least 150 minutes of PE each week, with $82 \%$ of secondary schools allocating at least 60 minutes for recess and lunchtime (combined) every day. ${ }^{5}$ The availability of PA facilities and equipment during 
school hours (as reported by school staff) is considered to be quite good at both primary ${ }^{19,29}$ and secondary schools. ${ }^{5}$ The confidence rating assigned to the data for this indicator was 2 stars (ie, representative but lacked robustness).

\section{Community and the Built Environment- Infrastructure, Policies, Programs, Safety: A-}

As in 2014, Community and the Built Environment was assigned an $A$-. This grade reflects a combination of primary metrics that represent the infrastructure, policies, programs and safety inherent within a child's immediate and wider community and built environment that could potentially impact PA participation. New national- and state-based data were available (see Table 1). Longitudinal data collected in 2010, 2012, and 2014 showed that $74 \%$ to $79 \%$ of parents do not consider heavy traffic to be a problem in their neighborhood. ${ }^{16,27,30}$ In regards to safety within the community, $96 \%$ of parents ${ }^{16}$ and $71 \%$ to $76 \%$ of children aged 12 to 17 years ${ }^{4,5}$ consider their neighborhood to be safe. The majority of parents believe that their children have access to a park/playground (85\%), good roads and footpaths (75\%) and public transport $(76 \%)^{16}$ within their neighborhood. Similarly, $76 \%$ of children aged 12 to 17 years report having access to a park/playground within their neighborhood. ${ }^{5}$ The confidence rating assigned to the data for this indicator was 1 star (ie, representativeness and robustness are lacking).

\section{Government-Strategies, Policies, Investments: D}

Government was assigned a $D$, which is worse than the $C+$ assigned in 2014. New state-based data were available (see Table 1) which shows that the majority of parents, children, and youth do not know what the national PA and sedentary behavior screen guidelines are, ${ }^{14}$ and this lack of knowledge is much worse for the PA guidelines. ${ }^{29,31,32}$ The RWG also considered initiatives that had been removed since the 2014 Report Card (eg, the Active After School Communities and National Partnership Agreement on Preventative Health initiatives ${ }^{33}$ ) and those that had been implemented (eg, Sporting Schools and the 'Girls Make Your Move' campaign) but are yet to be evaluated and may need to consider how to increase their effectiveness to appeal to all Australian children and youth, by imbedding strong underpinning framework that supports real behavior change and encourages lifelong activity participation. While many nongovernment organizations have lobbied for a funded National Physical Activity Plan (eg, the National Heart Foundation of Australia's 'Move More, Sit Less' campaign ${ }^{34-36}$ ), the Australian Government has failed to put anything into action, despite approximately 37 countries around the world establishing their own National Physical Activity Plan. Since the 2014 Report Card, the RWG believe the Australian Government has removed some major positive initiatives and introduced others with more limited potential. Improving Australia's PA grades will be hard without an overarching national plan or strategy forging a united way forward to get more Australian children and young people sufficiently active. Given the nature of this indicator no confidence rating was given.

\section{Physical Fitness: C-}

Physical Fitness was assigned a $C$-, representing the first time that a letter grade was assigned to this indicator. In addition to the statebased data considered in $2014,{ }^{29}$ new state-based data were available in 2016. ${ }^{22,37}$ Collectively, these data, which represented more than 5800 9- to 16-year-olds from multiple states and territories who were directly measured using the $20 \mathrm{~m}$ shuttle run (20mSRT), were believed by the RWG to be sufficient to confidently inform a grade. Relative to sex-specific and age-specific international normative $20 \mathrm{mSRT}$ values generated on 1,142,026 children and young people from 50 countries, ${ }^{38}$ Australian children and young people are of below average aerobic fitness (mean $\pm 95 \%$ confidence interval: 43 \pm 5 percentile). ${ }^{22,29,37}$ The confidence rating assigned to the data for this indicator was 2 stars (ie, robust but not representative).

\section{Movement Skills: $D$}

Movement Skills was assigned a $D$, representing the first time that a letter grade was assigned to this indicator. While no new data were available, the RWG decided a grade assignment was justified given the addition of the confidence rating (ie, 2 stars), which reflected the robustness of the measure (Get Skilled Get Active process-oriented checklists $\left.{ }^{39}\right)$ that was administered in a considerable sized random (at the school-level) sample ( 7800) on school children from NSW in grades 2 to 10 . On average, $23 \%$ of boys and 29\% of girls (in Grade 6) demonstrated mastery in locomotion (sprint, vertical jump, side gallop and leap) and $43 \%$ of boys and $17 \%$ of girls (in Grade 6) showed mastery in object-control (kick, over-arm throw and catch) skills. ${ }^{29}$ The confidence rating assigned to the data for this indicator was 2 stars (ie, robust but not representative).

\section{Strengths and Limitations}

The AHKA Report Card initiative is driven by a strong RWG that comprised research leaders in the field of children and youth PA and health from around Australia. The 2016 grades are based on the best available data from 18 surveys (6 national- and 12 statebased) collected from 2010 onwards, representing approximately 120,000 children aged 2 to 17 years, and provide a meaningful national snapshot of how young Australians are faring in regards to their PA levels.

Despite this, research gaps are present. The majority of grades assigned were based on self-report data, and those grades based on objective data (eg, Physical Fitness and Movement Skills) were reliant on state-level rather than national-level data. $22,29,37$ Both at the national- and state-level, quality, resolution, consistency, and age-based representation of the data being collected need further consideration. Specifically, there needs to be harmonization (at the state, national and international level) so that all PA data on children are collected via standardized instruments and metrics. This is vital to achieve a better understanding of current and future PA behaviors of all children and youth.

\section{Conclusion}

The 2016 AHKA Report Card showed that the overall PA levels of Australian children and youth are low, and that the time they spend sedentary and engaged with screens is high. As in 2014, the 2016 Report Card revealed that a disparity still exists between support structures (eg, infrastructure, supports, policies and programs in various settings [eg, family and peers, community, school]) and overall PA levels, because while the support structures seem to be in place the overall PA level of Australian children and youth is low. We lack an overarching National Physical Activity Plan that would unify the country's response to the inactivity crisis we are facing. In addition to this the implementation of a standardized PA monitoring system at the federal level would ensure consistent reporting and 
surveillance of Australia's PA levels. A cultural shift is required and conscious action needed to ensure that all Australian children and young people develop the level of physical literacy required to become confident, competent, motivated and knowledgeable PA participants for life.

\section{Acknowledgments}

The 2016 AHKA Report Card used unit record data from the Growing Up in Australia, the Longitudinal Study of Australian Children. The study is conducted in partnership between the Department of Families, Housing, Community Services and Indigenous Affairs (FaHCSIA), the Australian Institute of Family Studies (AIFS) and the Australian Bureau of Statistics (ABS). The findings and views reported in this paper are those of the author and should not be attributed to the FaHCSIA, the AIFS or the ABS. The 2016 AHKA Report Card used data from the 2009/10 and 2012/13 National Secondary Students' Diet and Activity (NaSSDA) survey. We acknowledge funding for the NaSSDA survey was sought from Cancer Council Australia and the National Heart Foundation of Australia and State and Territory Government Health Departments. The 2016 Report Card also used data that was collected, managed and/or provided/authorized by: ACT Health, ACT Education and Training Directorate staff and the ACT Chief Health Officer (ACT PANS); The Australian Chief Investigators of ISCOLE, Professor Tim Olds and Dr Carol Maher from the University of South Australia; the NSW Ministry of Health (NSW CPHS, NSW SSHBS and SPANS); Flinders University and SA Health (OPAL); the Queensland Department of Health, Prevention Division, Preventive Health Branch (QLD CHSS); SA Health and Population Research and Outcomes Studies, The University of Adelaide (SAMSS); the SmartStart for Kids charity and Robert de Castella (SmartStart); the Research Institute for Sport and Exercise (UCRISE) at the University of Canberra, The Clinical Trials Unit at the Canberra Hospital, the College of Medicine, Biology and Environment at the Australian National University, The Bluearth Foundation, ACT Pathology at the Canberra Hospital, Deakin University and The Commonwealth Education Trust (LOOK); and the Victorian Department of Education and Training (VSHAWS and VCHWS). It is acknowledged that opinions expressed in this manuscript are those of the authors not of the above mentioned individuals, organizations, universities, institutes or government departments/branches. AHKA is supported by the University of South Australia through funding from the Vice Chancellor's Development Fund. NKS is supported by the Vice Chancellor's Development Fund. DRL is supported by an Australian Research Council Future Fellowship (FT140100399). KDH is supported by an Australian Research Council Future Fellowship (FT130100637) \& Honorary National Heart Foundation of Australia Future Leader Fellowship (100370).

\section{References}

1. Schranz N, Olds T, Cliff D, et al. Results from Australia's 2014 Report Card on Physical Activity for Children and Youth. J Phys Act Health. 2014;11(Supp 1):S21-S25. PubMed doi:10.1123/jpah.2014-0164

2. Australian Bureau of Statistics. Australian Health Survey: Physical Activity, 2011-12. 2013: Catalogue No. 4364.0. Canberra: Australian Bureau of Statistics.

3. Australian Bureau of Statistics. National Health Survey: First Results, 2014-15. 2015: Catalogue No. 4364.0.55.001. Canberra: Australian Bureau of Statistics.

4. Cancer Council Victoria. National Secondary Students' Diet and Activity (NaSSDA) survey, 2009-10. http://www.cancer.org.au/ preventing-cancer/nutrition-and-physical-activity/national-secondary-students-diet-and-physical-activity-survey.html
5. Cancer Council Victoria. National Secondary Students' Diet and Activity (NaSSDA) survey, 2012-13. http://www.cancer.org.au/news/ media-releases/increase-in-teenagers-screen-use-a-new-threat-tolong-term-health.html.

6. Janssen I, LeBlanc A. Systematic review of the health benefits of physical activity and fitness in school-aged children and youth. Int $J$ Behav Nutr Phys Act. 2010;7:40. PubMed

7. Okely A, Salmon J, Vella S, Cliff D, Timperio A, Tremblay M, Trost S, Shilton T, KHinkley T, Ridgers N, Phillipson L, Hesketh K, Parrish A, Janssen X, Brown M, Emmel J, and Marino N. A Systematic Review to update the Australian Physical Activity Guidelines for Children and Young People, 2012. Canberra, Australia: Commonwealth of Australia.

8. Whitehead M. Philosophical considerations in relation to developing a sense of self, universality and propositional knowledge, sport, ethics and philosophy. Sport Ethics and Philosophy. 2007;1(3):281-298. doi:10.1080/17511320701676916

9. Whitehead M. Definition of physical literacy and clarification of related issues. ICSSPE Bulletin. 2013;65(October):29-34.

10. Almond $\mathrm{L}$. What is the value of physical literacy and why is physical literacy valuable? ICSSPE Bulletin. 2013;65(October):35-41.

11. Active Healthy Kids Global Alliance. 2016. http://www.activehealthykids.org/. Accessed June 1, 2016.

12. Active Healthy Kids Australia. The Road Less Travelled: The 2015 Active Healthy Kids Australia Progress Report Card on Active Transport for Children and Young People. Adelaide, South Australia: Active Healthy Kids Australia; 2015.

13. Almond L. Physical literacy and its association with health. ICSSPE Bulletin. 2013;65(October):229-236.

14. Department of Health and Aging. National Physical Activity Guidelines for Australians, 2014, Commonwealth of Australia: Canberra; 2014.

15. Australian Bureau of Statistics. Children's Participation in Cultural and leisure Activities, Australia, 2012. 2012: Catalogue No. 4901.0. Canberra: Australian Bureau of Statistics.

16. Australian Institute of Family Studies. Growing Up in Australia, Longitudinal Study of Australian Children. Melbourne: LSAC; 2014.

17. Australian Sports Commission. Participation in Exercise. Canberra, Australia: Recreation and Sport; 2012.

18. Epidemiology Section ACT. Health, Year 6 ACT Physical Activity and Nutrition Survey, data collection: 2015: ACT.

19. Katzmarzyk P, Barreira T, Broyles S, et al. The International Study of Childhood Obesity, Lifestyle and the Environment (ISCOLE): design and methods. BMC Public Health. 2013;13:900. PubMed doi:10.1186/1471-2458-13-900

20. Queensland Government Department of Health. Child Health Status Survey, 2015 [unpublished data]. Preventive Health Branch 11 April 2016: Brisbane, Queensland.

21. Taylor A, Dal Grande E. Chronic disease and risk factor surveillance using the SA Monitoring and Surveillance System (SAMSS) - history, results and future challenges. Public Health Bulletin (Wash D C). 2008;5:17-21.

22. Telford R, Bass S, Budge M, et al. The lifestyle of our kids (LOOK) project: outline of methods. J Sci Med Sport. 2009;12:156-163. PubMed doi:10.1016/j.jsams.2007.03.009

23. Queensland Government Department of Health. Child Health Status Survey, 2011 [unpublished data]. Preventive Health Branch 20 March 2015, Brisbane, Queensland.

24. Australian Bureau of Statistics. Participation in Sport and Physical Recreation, Australia, 2009-10. 2009-10: Catalogue No. 4177.0. Canberra: Australian Bureau of Statistics. 
25. Queensland Government Department of Health. Child Health Status Survey, 2014 [unpublished data], Preventive Health Branch 20 March 2015: Brisbane, Queensland.

26. Centre for Epidemiology and Evidence NSW Ministry of Health. Child Population Health Survey, Centre for Epidemiology and Evidence NSW Ministry of Health, 2014: New South Wales. http://www.health. nsw.gov.au/surveys/child/Pages/default.aspx.

27. Australian Institute of Family Studies. Growing Up in Australia, Longitudinal Study of Australian Children. Melbourne: LSAC; 2012.

28. Department for Health and Ageing. Obesity Prevention and Lifestyle (OPAL) Evaluation [unpublished survey data]. Adelaide, South Australia: Department for Health and Ageing; 2013.

29. Hardy LL, King L, Espinel P, Okely A, Bauman A. Methods of the NSW schools physical activity and nutrition survey 2010 (SPANS 2010). J Sci Med Sport. 2011;14(5):390-396. PubMed doi:10.1016/j. jsams.2011.03.003

30. Australian Institute of Family Studies. Growing Up in Australia, Longitudinal Study of Australian Children. Melbourne: LSAC; 2010.

31. Centre for Epidemiology and Evidence NSW Ministry of Health. Child Population Health Survey, Centre for Epidemiology and Evidence NSW Ministry of Health, 2013: New South Wales. http://www.health. nsw.gov.au/surveys/child/Pages/default.aspx.

32. Queensland Government Department of Health. Child Health Status Survey, 2013 [unpublished data]: Preventive Health Branch 20 March 2015, Brisbane, Queensland.

33. Australian Government Department of Health. National Partnership Agreement on Preventive Health. 2013. https://health.gov.au/internet/ anpha/publishing.nsf/Content/npaph. Accessed March 27, 2014.

34. National Heart Foundation of Australia. 37 compelling reasons why Australia needs a National Physical Activity Action Plan. 2016. https:// www.heartfoundation.org.au/news/37-compelling-reasons-why-australia-needs-a-national-physical-activity-action-plan. Accessed May $20,2016$.

35. National Heart Foundation of Australia. One year on momentum builds behind move more, sit less. 2016. http://heartfoundation.org.au/news/ one-year-on-momentum-builds-behind-move-more-sit-less. Accessed May 20, 2016.

36. National Heart Foundation of Australia. Move more, sit less: Australia needs a funded National Physical Activity Action Plan (Canberra
Communiqué). Canberra: National Heart Foundation of Australia; 2015.

37. Cochrane T. (Personal Communication). SmartStart for Kids! (Aggregated Data), 2016: Centre for Research \& Action in Public Health, Health Research Institute, University of Canberra.

38. Tomkinson G, Lang J, Tremblay M, Dale M, LeBlanc A, Belanger $\mathrm{K}$, Ortega $\mathrm{F}$, and Leger L. International normative $20 \mathrm{~m}$ shuttle run values from 1142026 children and youth representing 50 countries. Br J Sports Med. 2016;0:1-14.

39. NSW Department of Education and Training. Get skilled: Get active. A $K$-6 resource to support the teaching of fundamental movement skills. Ryde, NSW: NSW Department of Education and Training; 2000.

40. Australian Bureau of Statistics. Participation in Sport and Physical Recreation, Australia, 2011-12. 2011-12: Catalogue No. 4177.0. Canberra: Australian Bureau of Statistics.

41. Epidemiology Section ACT Health. Year 6 ACT Physical Activity and Nutrition Survey, data collection: 2012: ACT.

42. Centre for Epidemiology and Evidence NSW Ministry of Health. Child Population Health Survey, Centre for Epidemiology and Evidence NSW Ministry of Health, 2010: New South Wales. http://www.health. nsw.gov.au/surveys/child/Pages/default.aspx.

43. Centre for Epidemiology and Evidence NSW Ministry of Health. Child Population Health Survey, Centre for Epidemiology and Evidence NSW Ministry of Health, 2012: New South Wales. http://www.health. nsw.gov.au/surveys/child/Pages/default.aspx.

44. Centre for Epidemiology and Evidence NSW Ministry of Health. School Students Health Behaviours Survey, Centre for Epidemiology and Evidence NSW Ministry of Health, 2011: New South Wales. http:// www.health.nsw.gov.au/surveys/student/Pages/default.aspx.

45. Centre for Epidemiology and Evidence NSW Ministry of Health. School Students Health Behaviours Survey, Centre for Epidemiology and Evidence NSW Ministry of Health, 2014: New South Wales. http:// www.health.nsw.gov.au/surveys/student/Pages/default.aspx.

46. Department of Education and Early Childhood Development. Victorian Student Health and Wellbeing Survey. Victoria: Department of Education and Early Childhood Development; 2014.

47. Department of Education and Early Childhood Development. Victorian Child Health and Wellbeing Survey (VCHWS). Victoria: Department of Education and Early Childhood Development; 2013. 